Running head: Evaluations of people with facial disfigurement

\title{
Evaluations of people depicted with facial disfigurement compared to those with mobility impairment.
}

Anna Stone ${ }^{1}$, Toby Wright

${ }^{1}$ Corresponding author

School of Psychology

University of East London

Water Lane

Stratford

London E15 4LZ

Email: A.Stone@uel.ac.uk 


\begin{abstract}
$\underline{\text { Abstract }}$
There are few extant studies of stereotyping of people with facial disfigurement. In the present study, two experiments (both within-participants) showed positive evaluations of people depicted as wheelchair users and, from the same participants, negative evaluations of people with facial disfigurements, compared to controls. The results of Experiment 2 suggested that implicit affective attitudes were more negative towards people with facial disfigurement than wheelchair users and were correlated with evaluation negativity. Social norms were perceived to permit more discrimination against people with facial disfigurement than against wheelchair users. These factors could help to explain the evaluative differences between the two disadvantaged groups.
\end{abstract}

Keywords: facial disfigurement, disability, stereotype, evaluations, trait, prejudice, implicit attitude, social norms. 


\section{$\underline{\text { Introduction }}$}

Negative stereotyping of relatively disadvantaged groups is a consistent phenomenon. For example, previous research has documented consistent negative evaluations of people with disabilities (e.g. Bell \& Klein, 2001; Fichten \& Amsel, 1986; Kelly, Sedlacek \& Scales, 1994; Loo, 2001; Louvet, 2007; Stone \& Colella, 1996). There is, however, relatively little research systematically documenting how people with facial disfigurement are viewed by the general population. The present research investigated the assumed personality traits and abilities of people with facial disfigurement in comparison with people with impaired mobility, in relation to the implicit attitudes of the perceiver and perceived social norms. The long-term utility of this research lies in the necessity of understanding how a particular group is viewed in order to plan appropriate campaigns to change negative and damaging views.

Stereotyping of people with disabilities. Several studies have examined how people with disabilities are evaluated, and a number of consistent factors have emerged (e.g. Eagly, Ashmore, Makhijani \& Longo, 1991; Fichten \& Amsel, 1986; Stone \& Colella, 1996; Kelly et al, 1994). People with disabilities are evaluated as being more quiet, shy, unsociable, and lower in interpersonal competence. They are also perceived as being less well emotionally adjusted (more anxious, depressed, and unstable) and more dependent on others. In addition, they are generally evaluated as lower in task competence and various skills commonly desired by employers. On the positive side, people with disabilities are seen as having greater integrity and concern for others (e.g. Fichten \& Amsel, 1986; Stone \& Colella, 1996), suggesting the operation of a 'norm to be kind' so that people with a disability are given superior evaluations in attributes that require no particular skill or competence (e.g. Nordstrom, Huffaker \& Williams, 1998; Stone \& Colella, 1996)

Fiske, Cuddy, Glick and Xu (2002) proposed a model with two major dimensions of competence and warmth against which people are commonly evaluated. According to these authors, people with disabilities are the subject of paternalistic stereotypes which portray them as lacking in competence but 
strong in warmth, along with other social groups including the elderly and the blind. People with facial disfigurement were not included in the Fiske et al (2002) study so we do not know how they might be positioned in the model.

Stereotyping of people with facial disfigurement. There is widespread belief that people with facial disfigurement are viewed negatively (e.g. Clarke, 1999; Hearst \& Middleton, 1997; Rumsey \& Harcourt, 2004; Walters, 1997) but there appears to be little empirical data. Research has tended to report similar views to those of people with disabilities regarding social skills and confidence. For example, Bull and David (1986) found that people with a small scar on their face were perceived as less sociable and confident than people without a visible scar. Stevenage and McKay (1999) reported lower evaluations of a person with a port-wine stain than a non-disfigured control over a range of items including several tapping into social confidence and skills. Rumsey, Bull and Gahagan (1986) reported that 11-year old children found people with facial disfigurement to be more angry and frightening, but also more friendly and helpful.

A more substantial body of research illustrates negative evaluation of unattractive individuals even in the population of people who could not be classed as having a disfigurement. The meta-analysis by Eagly, Ashmore, Makhijani and Longo (1991) reported that people with unattractive (but not disfigured) faces were strongly and consistently rated as lacking in social skills and confidence; and less strongly rated as lower in intellectual competence and various skills valued by employers, and lower in emotional adjustment. These are consistent with the evaluations of people with physical disabilities.

In addition to the empirical data there are several theoretical reasons to think that evaluations might be negative for people shown with a facial disfigurement. The face is a particularly important source of information in person perception (e.g. Zebrowitz, 1997; Berry \& Wero, 1993) and often the focus of attention in conversation. An evolutionary approach suggests that the apparent health and particularly the symmetry of a face are believed to be indicative of the quality of the individual's genes, and of their general fitness and intelligence (e.g. Thornhill \& Gangestad, 1993; Zebrowitz \& Rhodes, 2002). 
Despite these empirical and theoretical considerations, the current position regarding stereotyping of people with facial disfigurement is not entirely clear. For example, in a more recent study, Stevenage and Furness (2007) found that people portrayed with or without a facial port-wine stain were evaluated as equivalent on sociability and emotionality (Experiment 1 ) or sociability and strength of character (Experiment 2). It is relevant to note that the social mood in recent years has become much more inclusive and valuing of diversity. The impact of the Disability Discrimination Act of 2004 (in the UK) has been significant for people who work with members of the public. Training to promote concepts of diversity and inclusivity is widely available in large organizations and those in the public sector. The overall impact is much more social awareness of the need to treat people with disability or disfigurement fairly and equitably. An individual may therefore take increased care when expressing an opinion, even anonymously, and this could perhaps account for the findings of no negative stereotyping in the Stevenage and Furness (2007) study.

Devine (1989) explains that individual knowledge structures contain both stereotypes and personal beliefs regarding members of particular social groups, and that a personal belief may differ from a prejudicial stereotype. The stereotype will be automatically activated by the perception of a member of the social group, but it need not dominate responses. It has been suggested (e.g. Devine, 1989; Pryor, Reeder, Yeadon \& Hesson-Mclnnis, 2004) that a perceiver may have two psychological systems for generating responses: reflexive (fast-acting and automatic) arising from the stereotype; and reflective (slower and deliberative) arising from personal values. Thus, an individual with personal values and beliefs about the importance of fair and equal treatment of all individuals regardless of physical appearance may be able to censor a reflexive prejudicial response and institute a more appropriate reflective response instead. Thus, there are factors contributing to prejudice against people with facial disfigurement, and other factors working to negate the open expression of such prejudice. The investigations reported here aimed to clarify the present situation. 
The present series of Experiments. The aim of this series of experiments was to investigate evaluations of personality and abilities applied to individuals depicted with a facial disfigurement in comparison with images of the same individuals with no disfigurement. The target individuals were also shown either standing up or sitting in a wheelchair in order to be able to compare the impact of facial disfigurement with the impact of mobility impairment. Experiment 2 confirmed the pattern of results observed in Experiment 1and examined potential explanations in terms of implicit attitudes and perceived social norms.

\section{Experiment 1}

\section{Method}

Participants. There were 55 participants, 39 female and 16 male, aged between 18 and 62, mean 32.3, s.d. 11.3 years, mostly undergraduate students or recent graduates, and mostly resident in London. They were expected to be aware of the need to show respect and equal treatment for people with disability or facial disfigurement since this is made explicit in the University of East London Student Charter with which all students are required to become familiar. Other universities in the UK take a very similar approach.

Stimuli. Research to date on perceptions of people with facial disfigurement appears to address mostly people with minor skin blemishes, i.e. small areas of facial scarring or port-wine stain (e.g. Bull \& David, 1986; Houston \& Bull, 1994; Stevenage \& McKay, 1999). This may not reveal the extent of stereotyping that exists for people with more pronounced disfigurement. Another consideration is the expectation that a person with a skin blemish could cover this with make-up if they wanted to which might lead to speculation about the motive for not doing so. Therefore, the stimuli used here showed individuals with structural disfigurements that could not readily be disguised. This was considered an appropriate comparison with people shown as wheelchair users, itself a severe mobility impairment requiring adaptations to transport, working and living environments. Because of the lower frequency of media portrayal of people with facial disfigurement 
compared to wheelchair users it was not possible to equate these stimuli on familiarity, or perceived realism, or any factor depending on visual experience.

Photographs of patients were obtained from the Facial Surgery Research Foundation, two male and two female, one of each gender with a disfigurement to the eyes and one to the mouth. To protect their identity but preserve the disfigurement the faces were morphed with the faces of strangers obtained from the internet. The original stranger photographs were kept as control stimuli making a total of 8 faces, 4 disfigured and 4 controls. Ten students of the University of East London were unable to distinguish the 4 original faces from the 4 created faces [measuring the likelihood of each face being chosen yielded independent-samples $\mathrm{t}(6)=0.55, \mathrm{~ns}$ ]. Two colleagues of the researcher, one male and one female, posed for the body photographs in smart dress. Each was photographed in two postures: standing up and sitting in a wheelchair. Each of the 8 stranger faces was added to the two body photographs of the appropriate gender to make a total of 16 stimuli (see Appendix 1).

The rating scales were taken from those used by Stevenage and McKay (1999; please note no factor structure was reported) and modified to make sure that 4 areas were covered: work-related competence; social skills and potency; emotional strength and autonomy; and warmth and integrity. The resulting 18 semantic differential scales are listed in appendix 2 .

Design. The design was a $2 \times 2$ within-participants design. The two independent variables were face type (disfigured versus control) and posture (wheelchair versus standing). The dependent variables were the evaluations given to the target photographs on the 18 rating scales. Each participant responded to a set of four photographs as shown in Table 1. Each set contained four different facial identities and the facial identities were rotated around the conditions so that each identity appeared equally often in each condition. As shown in Table 1 target gender was counterbalanced with posture, and with disfigurement, but not with the interaction of posture and disfigurement. The third factor was target-sex counterbalance, with two levels. In level 1 the disfigured-wheelchair and control-standing faces were female 
while the disfigured-standing and control-wheelchair faces were male. Level 2 used the converse arrangement.

Table 1: stimulus counterbalancing for Experiment 1 and 2.

\begin{tabular}{|c|c|c|c|c|}
\hline Set & $\begin{array}{c}\text { Disfigured } \\
\text { Wheelchair }\end{array}$ & $\begin{array}{c}\text { Control } \\
\text { Wheelchair }\end{array}$ & $\begin{array}{c}\text { Disfigured } \\
\text { Standing }\end{array}$ & $\begin{array}{l}\text { Control } \\
\text { Standing }\end{array}$ \\
\hline$A$ & $\begin{array}{l}\text { Identity } 1 \\
\text { Female } \\
\text { Mouth }\end{array}$ & $\begin{array}{l}\text { Identity } 2 \\
\text { Male } \\
\text { Mouth }\end{array}$ & $\begin{array}{l}\text { Identity } 3 \\
\text { Male } \\
\text { eye }\end{array}$ & $\begin{array}{l}\text { Identity } 4 \\
\text { Female } \\
\text { eye }\end{array}$ \\
\hline B & $\begin{array}{l}\text { Identity } 4 \\
\text { Female } \\
\text { Eye }\end{array}$ & $\begin{array}{l}\text { Identity } 3 \\
\text { Male } \\
\text { Eye }\end{array}$ & $\begin{array}{l}\text { Identity } 2 \\
\text { Male } \\
\text { mouth }\end{array}$ & $\begin{array}{l}\text { Identity } 1 \\
\text { Female } \\
\text { mouth }\end{array}$ \\
\hline C & $\begin{array}{l}\text { Identity } 3 \\
\text { Male } \\
\text { Eye }\end{array}$ & $\begin{array}{l}\text { Identity } 4 \\
\text { Female } \\
\text { Eye }\end{array}$ & $\begin{array}{l}\text { Identity } 1 \\
\text { Female } \\
\text { mouth }\end{array}$ & $\begin{array}{l}\text { Identity } 2 \\
\text { Male } \\
\text { mouth }\end{array}$ \\
\hline D & $\begin{array}{l}\text { Identity } 2 \\
\text { Male } \\
\text { Mouth }\end{array}$ & $\begin{array}{l}\text { Identity } 1 \\
\text { Female } \\
\text { Mouth }\end{array}$ & $\begin{array}{l}\text { Identity } 4 \\
\text { Female } \\
\text { eye }\end{array}$ & $\begin{array}{l}\text { Identity } 3 \\
\text { Male } \\
\text { Eye }\end{array}$ \\
\hline
\end{tabular}

Procedure. Participants were informed that the purpose of the study was to investigate perceptions of people with different appearance.

Participants were assured that they could withdraw at any time and that their responses would be anonymous, and they signed a consent form to indicate agreement to participate.

Each participant was given a booklet of 4 photographs, each accompanied by the 18 trait scales on the facing page. The sequence of the 18 scales was randomised for each participant but was the same for each of the 4 photographs in a booklet. Participants were asked to evaluate the person depicted in the photograph on a scale of 1 to 6 . The direction of half the scales was reversed so that the positive pole appeared sometimes on the left and sometimes on the right.

Participants were informed that there were no correct answers and that they should proceed at their own pace but without thinking too long about their answers. Participants were also asked for their age and gender, and a small set of questions about their degree of contact with any wheelchair user or 
anyone with a facial disfigurement. On completion of the questionnaires participants were debriefed.

\section{Results}

The 18 traits were grouped into the 4 categories that were identified in the introduction as distinguishing between stereotypes of people with and without disabilities. The composites and individual traits were as follows. Work competence comprised Intelligent, Copes with pressure, Decisive, Shows initiative, Good organisational skills, Good interpersonal skills, and Pays attention to detail. Social potency comprised Outgoing, Competitive, Assertive, Prefers teamwork, and Can work with people from different backgrounds. Emotional strength comprised the inverse of Sensitive and Emotional and the trait Strong leader. Warmth comprised the traits Friendly and Trustworthy. These four composites were analysed separately because of evidence that they might not all differentiate equally strongly on the basis of facial disfigurement or wheelchair use (e.g. Eagly et al, 1991), and evidence that the Warmth composite might be rated higher for disadvantaged individuals (e.g. Eagly et al, 1991; Fiske et al, 2002). The interpersonal skills trait was included with Work competence rather than Social potency after an exploratory factor analysis showed that it was more associated with Work competence. An alternative analysis with the good interpersonal skills trait included in the Social potency composite and not in the Work competence composite made no salient difference to the pattern of results.

The trait Attractive was included to ascertain that participants were not trying too hard to give socially desirable responses by checking that the target individuals with facial disfigurement, or those in a wheelchair, were not rated as being much more attractive than their corresponding controls.

Photograph Ratings. For each target photograph four composites were calculated as the mean of the individual ratings that comprised the composite. A series of $2 \times 2 \times 2$ ANOVA were performed to compare ratings on each of the four composites. The factors of posture (standing vs. wheelchair) and face type (disfigured vs. control) were both varied within-participants, and the factor 
of target sex counterbalance was varied between participants ${ }^{1}$. The results of the Anova are shown in Figure 1 and Table 2.

On the trait composite of Work competence, persons in a wheelchair were rated as higher than those shown standing $[F(1,53)=17.51, p<0.001]$. There was no main effect of face type $[F(1,53)=3.80, p>0.05]$ but there was a three-way interaction of posture with face type and target sex counterbalance $[F(1,53)=9.64, p<.005]$. A series of independent samples $t-$ tests revealed that there was no effect of target sex in the disfiguredwheelchair or disfigured-standing conditions [both $t<1$ ]. Females were rated higher than males in the control-wheelchair condition $[t(53)=2.20, p<0.05]$ and in the control-standing condition $[\mathrm{t}(53)=3.38, \mathrm{p}<0.005]$.

On the trait composite of Social potency, persons in a wheelchair were rated as higher than those shown standing $[F(1,53)=16.09, p<0.001]$. Persons with facial disfigurement were rated as lower than those without facial disfigurement $[F(1,53)=6.01, p<0.05]$. There was also a three-way interaction of posture, face type and target sex counterbalance $[F(1,53)=$ 5.94, $p<0.05$ ] showing the same pattern as Work competence. A series of independent samples t-tests revealed that there was no effect of target sex in the disfigured-wheelchair or disfigured-standing conditions [both $t<1$ ]. Females were rated marginally higher than males in the control-wheelchair condition $[\mathrm{t}(53)=1.75, \mathrm{p}<0.1]$ and higher than males in the control-standing condition $[\mathrm{t}(53)=2.83, \mathrm{p}<0.01]$.

On the trait composite of Emotional strength, persons with facial disfigurement were rated as lower than those shown without facial disfigurement $[F(1,53)=5.78, p<0.05]$. There was no main effect of posture $[F<1]$ and no three-way interaction of posture, face type and target sex counterbalance $[\mathrm{F}<1]$.

On the trait composite of Warmth, persons in a wheelchair were rated higher than those shown standing $[F(1,53)=7.22, p<0.01]$. Persons shown with facial disfigurement were rated higher than those without facial

\footnotetext{
${ }^{1}$ As noted earlier, the third factor was target-sex counterbalance, with two levels. In level 1 the disfigured-wheelchair and control-standing faces were female while the disfigured-standing and control-wheelchair faces were male. Level 2 used the converse arrangement.
} 
disfigurement $[F(1,53)=6.15, p<0.05]$. There was also a three-way interaction of posture, face type and target sex counterbalance $[F(1,53)=$ 4.36, $p<0.05$ ], similar but weaker to the pattern on the traits of Work competence and Social potency. A series of independent samples t-tests revealed that females were rated higher than males only in the controlstanding condition $[t(53)=2.58, p<0.02)]$ and not in the control-wheelchair, disfigured-standing or disfigured-wheelchair conditions [all $\mathrm{t}<=1$ ].

There was no interaction between the two factors of disfigurement and posture on any of the four composites, all $F<1.2$, suggesting that the experimental factors acted independently of each other. This offers no support for the hypothesis that the effects of a facial disfigurement might modify the effects of a functional impairment or vice versa.

To check the ratings of attractiveness, paired-samples t-tests examined the simple effect of wheelchair use only for people without disfigurement, and the simple effect of disfigurement only for people shown standing. Target individuals shown with facial disfigurement were rated as less attractive than those shown without disfigurement $[\mathrm{t}(53)=3.66, \mathrm{p}<0.005$; degrees of freedom differ from the other factors because one participant declined to rate the target photographs on the trait of attractiveness]. Target individuals shown in a wheelchair were rated as slightly more attractive than those shown standing $[\mathrm{t}(53)=2.80, \mathrm{p}<0.05]$ but this difference was not more than one point on the rating scale for any participant. These results suggest that participants' responses were not deformed by social desirability motives to an unacceptable degree.

Participants were more likely to know someone who uses a wheelchair $(46 \%)$ than someone with a facial disfigurement $(27 \%)$. The acquaintance with a facial disfigurement was less likely to be a close friend or relative $(33 \%)$ than a casual acquaintance (60\%). In comparison, the acquaintance who uses a wheelchair was more likely to be a close friend or relative (68\%) and less likely to be a casual acquaintance $(24 \%)$. 
A: Work Competence

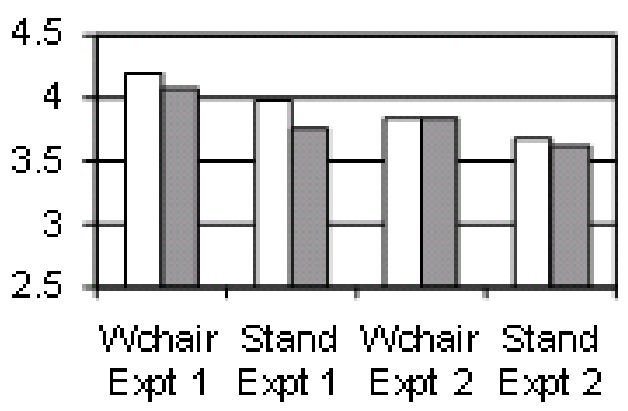

c: Emotional strength

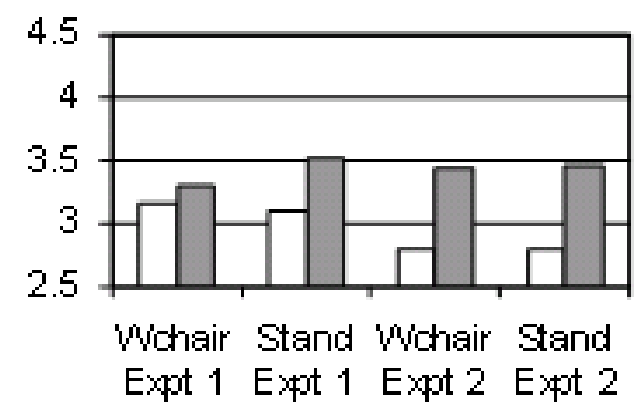

B: Social potency

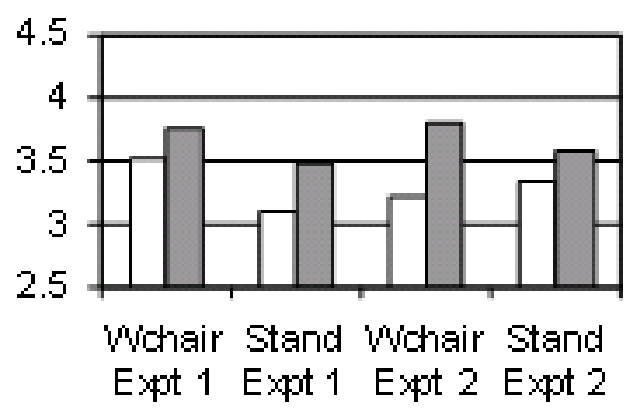

D: Wamth

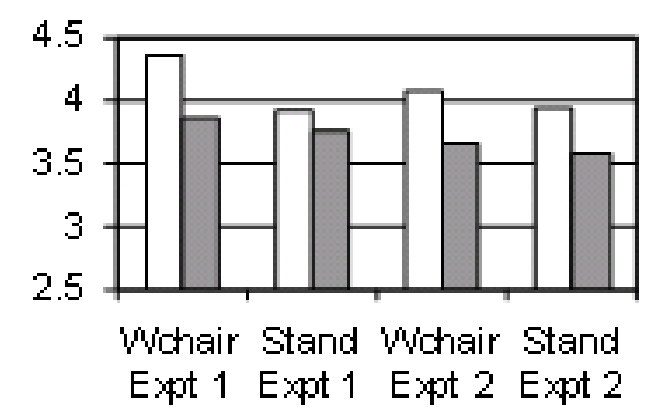

Figure 1: ratings of people depicted standing versus in a wheelchair and with and without facial disfigurement. Panel A: Work competence. Panel B: Social potency. Panel C: Emotional strength. Panel D: Warmth. White bars are disfigured faces, dark bars are control faces. 
Table 2: Means (s.d.) of ratings on the four composites in Expt 1 and 2.

\begin{tabular}{|c|c|c|c|}
\hline & & Ex 1 & Ex 2 \\
\hline \multirow[t]{6}{*}{ Work Competence } & Disfigured-Wheelchair & $4.19(0.52)$ & $3.83(0.68)$ \\
\hline & Disfigured-Standing & $3.98(0.62)$ & $+3.67(0.64)$ \\
\hline & Control-Wheelchair & $+4.08(0.69)$ & $3.83(0.61)$ \\
\hline & Control-Standing & $+3.76(0.77)$ & $3.62(0.64)$ \\
\hline & Disfigurement effect size & 0.25 & 0.04 \\
\hline & Posture effect size & ${ }^{*} 0.41$ & * 0.29 \\
\hline \multirow[t]{6}{*}{ Social Potency } & Disfigured-Wheelchair & $3.64(0.75)$ & $3.21(0.77)$ \\
\hline & Disfigured-Standing & $3.24(0.73)$ & $3.34(0.80)$ \\
\hline & Control-Wheelchair & $+3.78(0.78)$ & $3.79(0.78)$ \\
\hline & Control-Standing & $+3.55(0.64)$ & $3.57(0.75)$ \\
\hline & Disfigurement effect size & * -0.31 & * -0.52 \\
\hline & Posture effect size & * 0.43 & 0.06 \\
\hline \multirow[t]{6}{*}{ Emotional Strength } & Disfigured-Wheelchair & $3.15(0.86)$ & $2.80(0.75)$ \\
\hline & Disfigured-Standing & $3.10(0.83)$ & $2.79(0.72)$ \\
\hline & Control-Wheelchair & $3.30(0.78)$ & $3.43(0.78)$ \\
\hline & Control-Standing & $3.51(1.12)$ & $3.46(0.77)$ \\
\hline & Disfigurement effect size & ${ }^{*}-0.31$ & ${ }^{*}-0.86$ \\
\hline & Posture effect size & -0.09 & -0.01 \\
\hline \multirow[t]{6}{*}{ Warmth } & Disfigured-Wheelchair & $4.35(0.92)$ & $4.08(0.83)$ \\
\hline & Disfigured-Standing & $3.92(0.94)$ & $3.93(0.95)$ \\
\hline & Control-Wheelchair & $3.85(1.03)$ & $3.65(0.96)$ \\
\hline & Control-Standing & $+3.75(0.95)$ & $3.57(0.85)$ \\
\hline & Disfigurement effect size & * 0.35 & ${ }^{*} 0.44$ \\
\hline & Posture effect size & * 0.28 & 0.12 \\
\hline
\end{tabular}

${ }^{*}=$ significant at $p<0.05+=$ female targets rated higher than male targets

Table 2: Mean (s.d.) of ratings on the four composites calculated for each combination of posture with face type. Effect size is calculated as Cohen's $D$ (e.g. disfigurement effect size is the mean of the two disfigured conditions minus the mean of the two control conditions, divided by the pooled standard deviation). 


\section{Discussion}

The most striking feature of these results is the positive or neutral ratings of people shown in a wheelchair but neutral or negative evaluation of people shown with facial disfigurement, compared to controls. The only positive rating of people with facial disfigurement was on the factor of warmth and integrity. It was noted in the introduction that positive ratings on this type of factor may stem from the "norm to be kind" that produces positive evaluations of people from disadvantaged groups if the rating does not imply any particular skill or competence.

The observation of more positive ratings for people shown in a wheelchair compared to the same people shown standing, on the composites Work competence and Social potency, indicates that participants had been applying positive discrimination. It is interesting that no such bias seems to have been applied to the targets shown with facial disfigurement. The observation of different patterns of ratings of the two disadvantaged groups suggests the operation of complex and differentiated evaluative mechanisms, rather than a simple reflexive response of giving higher ratings to the disadvantaged target person. This will be explored further in Experiment 2.

There was no interaction between the two factors of wheelchair use and facial disfigurement. While the absence of interaction might suggest that these two attributes are considered and evaluated separately but one must be cautious in interpreting a null effect. In any event, the main thrust of the present research was the comparison between the two attributes rather than their interaction.

Women were rated higher than men in Work competence and Social potency as long as they were not shown with a facial disfigurement. They were also rated higher than men in Warmth but only in the standing, nondisfigured condition. This pattern suggests the presence of positive discrimination in favour of women (given that participants would have been aware of the existence of general gender discrimination in favour of men) that was neutralized by the presence of facial disfigurement. 


\section{Experiment 2}

The aim of Experiment 2 was to investigate underlying factors with potential explanatory value for the different patterns of evaluations of the two disadvantaged groups. Two factors seem particularly plausible: affective attitudes might be more negative towards people with disfigured faces than towards wheelchair users; and perceived social norms might suggest that discrimination would be more common and more acceptable towards people with facial disfigurement.

An affective attitude is defined here as 'a psychological tendency to evaluate a given entity with some degree of favor or disfavor' (Gawronski \& Bodenhausen, 2006, p693). There are several reasons to think that affective attitudes might be more negative towards people with facial disfigurement than towards wheelchair users. For example, Giancoli and Neimeyer (1983) reported that people with disfigured faces are less well liked than wheelchair users. The face is the centre of social interaction and is important as a source of information about the individual (e.g. Berry \& Wero, 1993; Thornhill \& Gangestad, 1993; Zebrowitz, 1997). Finally, in modern society a premium is placed on attractiveness (e.g. Andreoni \& Petrie, 2008; Dijker \& Koomen, 2001; Judge, Hurst \& Simon, 2009; Solnick \& Schweitzer, 1999). The relationship between affective attitudes and explicit evaluations (e.g. Gawronski \& Bodenhausen, 2006; Whitfield \& Jordan, 2009) could then help to explain the more negative evaluations of people with facial disfigurement. Experiment 2 employed adapted versions of the Implicit Association Test to investigate implicit affective attitudes towards people with facial disfigurement and people with mobility impairment.

The other potentially relevant factor is the perceived social norm for treatment of people with facial disfigurement and wheelchair users. If participants in Experiment 1 had perceived that the social norm permitted more discrimination against people with facial disfigurement than wheelchair users then this could also help to explain the observed results, assuming that participants' responses would be influenced by their perception of socially normative behaviour. To test this account, Experiment 2 used a short 
questionnaire to measure the perceived social norms for the treatment of people with facial disfigurement and wheelchair users.

The hypotheses were as follows. (1) People with facial disfigurement should be rated as equivalent in Work competence, lower in Social potency, lower in Emotional strength, and higher in Warmth, compared to the same people depicted without facial disfigurement; people shown in wheelchairs should be rated as higher in Work competence and Social potency, equivalent in Emotional strength, and higher in Warmth, compared to controls (as Experiment 1). Hypothesis (2) is that implicit attitudes should be more negative to people with facial disfigurement than to wheelchair users. Hypothesis (2a) is that the IAT effect for facial disfigurement should be correlated with the difference in the ratings given to targets shown with and without facial disfigurement. Similarly, hypothesis $(2 b)$ is that the IAT effect for wheelchair use should be correlated with the difference in the ratings given to targets shown with and without a wheelchair.

Hypothesis (3) is that the perceived social norm should permit more discrimination against people with facial disfigurement than against wheelchair users. Hypothesis (3a) is that the strength of the perceived social norm for facial disfigurement should be correlated with the difference in ratings of targets with and without facial disfigurement. Similarly, hypothesis (3b) is that the strength of the social norm for wheelchair users should be correlated with the difference in ratings of targets shown with and without a wheelchair.

\section{Method}

Participants. Participants were an opportunity sample $(n=72)$ of undergraduate and postgraduate students at the University of East London who responded to posters asking for volunteer participants, consisting of 51 females and 20 males of mixed ethnicity, of whom none had participated in a previous study (one participant declined to give their gender). They were aged between 18 and 50, mean 30 years (s.d. 9.1). Data from other participants with very low accuracy (below 40\%) in any block of the Implicit Association Test were excluded, consistent with (though more inclusive than) the 
procedure used by other researchers (e.g. Popa-Roch \& Delmas, 2010; Richetin \& Perugini, 2008).

Measures. The target photographs and rating scales from Experiment 1 were used again.

The Implicit Association Test (IAT; Greenwald, McGhee \& Schwartz, 1998) was used as a measure of affective attitude because it is hard for participants to fake without pre-warning (e.g. Banse, Seise, \& Zerbes, 2001; Pruett \& Chan, 2006; Steffens, 2004). The test - retest reliability of the IAT was calculated as a satisfactory alpha $=0.79$ overall in a recent meta-analysis (Hofmann, Gawronski, Gschwender, Le \& Schmitt, 2005). The IAT has been used to investigate implicit associations towards a diverse array of targets and topics including gay men (e.g. Banse, Seise \& Zerbes, 2001) and racism (e.g. Baron \& Banaji, 2006).

Two Implicit Association Tests for people with facial disfigurement and wheelchair users were presented on a laptop computer running EPrime software. Response times and accuracy were recorded by the programme. The basis of the IAT is that two types of stimuli, words and pictures, are each given a binary categorisation on alternate trials in the same block and that these stimuli use the same two response keys. So, for example, in one block of trials, the word category Good (e.g. joy, laughter) uses the $Z$ key and the word category Bad (e.g. death, torment) uses the M key, while the face category Distinctive uses the $Z$ key and the face category Typical uses the $M$ key. This block would be referred to as the Good-Distinctive block.

The robust and consistent finding of the IAT is that participants perform faster in a block in which members of advantaged social groups are paired with good words by using the same response key than in a block in which members of disadvantaged groups are paired with good words. This holds true when participants are members of the advantaged group, as was the case in the present study. The magnitude of the IAT effect, calculated as the latency difference between the two types of blocks, is assumed to reflect the strength of the individual participant's implicit affective attitude. 
In the Disfigurement IAT the terms Distinctive and Typical were chosen to define the face categories in order to avoid using the word "disfigured" which might bias participants towards a negative response. The faces were the 4 disfigured and 4 non-disfigured faces from Experiment 1.

Careful consideration was given to the choice of photographs for the wheelchair IAT. Version 1 used the same photographs as the trait evaluations, that is, images of people standing up vs. sitting in a wheelchair. The potential drawback was that the contrast might be too visually dissimilar and the difference in posture could create a spurious IAT effect; a particular consideration given the requirement for participants to respond quickly. Therefore, version 2 presented images of 4 people sitting in wheelchairs and 4 people sitting normally, obtained from the internet. The 4 non-disfigured faces were edited onto the torsos of these images in order to equalise the attractiveness of the images in both versions. All the photographs measured $150 \times 200$ pixels and were presented in greyscale against a neutral background, in the centre of the screen. Examples of stimuli used in the IAT are shown in Appendix 1. The IAT was run in two versions and the results were compared to verify their equivalence.

It should be noted that the IAT used general good and bad words (e.g. laughter, death) rather than specific trait descriptions (e.g. intelligent, friendly). Therefore it measured only the valenced attitude towards wheelchair users and people with facial disfigurement rather than semantic associations or trait stereotypes. This design was chosen because the alternative of measuring specific semantic associations would have been too time-consuming and tiring for participants. This limitation could restrict the strength of relationship that might be expected between the IAT effect and explicit trait evaluations.

A new instrument (see appendix 3) was designed to measure perceived social norms regarding the treatment of people with facial disfigurement or wheelchair users. A set of questions was assembled following consultation with colleagues and informal piloting established that participants found the questions meaningful and had no difficulty in answering them. Examples of questions are: "Other people often behave in a prejudiced way towards a person who uses a wheelchair" and "Discrimination against a 
person who uses a wheelchair is not acceptable" (reverse scored). These items were designed to probe both descriptive and prescriptive social norms. It is possible that descriptive and prescriptive social norms may exert different effects in the context of attitudes towards people with disability or disfigurement, but that was beyond the scope of the present investigation. The response to each question ranged from 1 (strongly disagree) to 9 (strongly agree). Both versions of the questionnaire were administered to all participants.

Design. The evaluation task had the same design as Experiment 1. Thus, the counter-balancing of stimuli across the two factors of disfigurement (disfigured vs. non-disfigured) and posture (wheelchair vs. standing) used the same arrangement as Experiment 1.

The IAT had two within-participant factors: condition (wheelchair vs. disfigurement) and type of block (Good-distinctive or Good-wheelchair vs. Good-typical or Good-non-wheelchair). The sequence of blocks was always as follows: word categorisation practice trials, then picture categorisation practice trials, then a combined block of words and pictures, then practice trials in the reversed-key categorisation of pictures, and finally a second block of combined words and pictures that complemented the first block e.g. if the first block was Good-Distinctive then the second block was Good-Typical. Half the participants performed the facial disfigurement IAT before the wheelchair IAT, and the other half did the reverse sequence. Half the participants in each version of the IAT performed the Good-Distinctive block before the GoodTypical block, and the other half of the participants performed the alternative sequence. Twenty participants performed the standing version of the wheelchair IAT and fifty-one participants performed the sitting-normally version. The larger sample was in the condition in which the IAT effect might have been smaller and the exact numbers of participants were determined by opportunity. Participants were asked to respond as quickly as possible without making too many mistakes. Errors were corrected in the practice trials, but were not corrected in the experimental blocks.

Procedure. Participants performed the experimental tasks individually. The series of tasks was explained and informed consent was given. 
Participants were assured that their responses would be treated as strictly anonymous.

First, participants gave their evaluations of the target images as in Experiment 1. After this participants completed both versions of the IAT. Then participants completed both the Social Norms questionnaires, in a counterbalanced sequence. They were asked to complete the questionnaires honestly without thinking too long about each answer. Finally, participants were thanked for their participation, given a verbal and written debriefing, and the researcher answered questions.

\section{Results}

Photograph ratings.

The same four rating composites from Experiment 1 were calculated again. A series of $2 \times 2 \times 2$ ANOVA were performed to compare ratings on each of the four composites. The factors of posture (standing vs. wheelchair) and face type (disfigured vs. control) were both varied within-participants, and the factor of target sex counterbalance was varied between participants. The results of the Anova are shown in Figure 1 and Table 2.

On the trait composite of Work competence, persons in a wheelchair were rated as higher than those shown standing $[F(1,70)=7.95, p<0.005]$. There was no main effect of face type $[F<1]$. The three-way interaction of posture with face type and target sex counterbalance was near-significant $[F(1,70)=3.91, p=0.052]$ but did not resemble the pattern shown in Experiment 1. A series of independent samples t-tests revealed that there was no effect of target sex in the disfigured-wheelchair, control-wheelchair or control-standing conditions, but females were rated higher than males in the disfigured-standing condition $[\mathrm{t}(70)=2.73, \mathrm{p}<0.01$.

On the trait composite of Social potency, persons with facial disfigurement were rated as lower than those without facial disfigurement $[F(1,70)=16.59, p<0.001]$. There was no main effect of posture $[F<1]$ but an interaction with disfigurement $[F(1,70)=6.66, p, 0.02]$, and pairedsamples t-tests revealed that people shown in a wheelchair were higher on 
Social potency only in the non-facially disfigured condition [paired-samples $t(71)=1.82, p<0.05$, one-tailed] but not in the facial disfigurement condition $[\mathrm{t}(71)=1.26, \mathrm{~ns}]$. It appears that the attribute of facial disfigurement abolished the positive discrimination shown towards a target individual in a wheelchair although this effect had not been apparent in Experiment 1. There was no three-way interaction of posture with face type and target sex counterbalance $[\mathrm{F}<1]$.

On the trait composite of Emotional strength, persons with facial disfigurement were rated as lower than those shown without facial disfigurement $[F(1,70)=52.8, p<0.001]$. No other effects were significant.

On the trait composite of Warmth, persons shown with facial disfigurement were shown as higher than those without facial disfigurement $[F(1,70)=15.93, p<0.001]$. No other effects were significant.

To check the ratings of attractiveness, paired-samples t-tests examined the simple effect of wheelchair use only for people without disfigurement, and the simple effect of disfigurement only for people shown standing. Target individuals shown with facial disfigurement were rated as less attractive than those shown without disfigurement $[\mathrm{t}(71)=3.75, \mathrm{p}<0.001]$. Target individuals shown in a wheelchair were rated as equivalently attractive to those shown standing $[t(71)=1.28, n s]$. These results suggest that participants' responses were not noticeably biased by social desirability motives.

Participants were more likely to know someone who uses a wheelchair (53\%) than someone with a facial disfigurement (35\%), and the acquaintance with a facial disfigurement was less likely to be a close friend or relative $(7 \%)$ and more likely to be a casual acquaintance (28\%). The acquaintance with a wheelchair was relatively more likely to be a close friend or relative $(18 \%)$ and relatively less likely to be a casual acquaintance (35\%). This is again similar to Experiment 1.

Implicit Association Test.

The IAT effect in each task was calculated according to the algorithm recommended in Greenwald, Nosek and Banaji (2003). This yielded mean 
response times in each block: Good-Typical, Good-Distinctive, Good-nonWheelchair, and Good-Wheelchair, which were then differenced (e.g. GoodDistinctive minus Good-Typical) and divided by the pooled standard deviation to give a wheelchair effect and a disfigurement effect. The IAT effects are illustrated in Figure 2. The predicted picture of faster responses in the Goodnon-Wheelchair and Good-Typical blocks than in the Good-Wheelchair and Good-Distinctive blocks can be seen in the positive sign of the IAT effect.

Anova was performed with two factors of IAT task (disfigurement vs. wheelchair; within-participants) and task sequence (wheelchair first vs. disfigurement first; between participants). There was a main effect of IAT task $[F(1,70)=18.7, p<0.001]$ showing a larger effect in the disfigurement task than in the wheelchair task. The main effect of task sequence and the interaction were both non-significant [both $\mathrm{F}<1.4]$. One-sample t-tests confirmed that the IAT effect was significant in the wheelchair task $[\mathrm{t}(71)=$ $10.1, p<0.001]$ and the disfigurement task $[(t(71)=15.0, p<0.001]$.

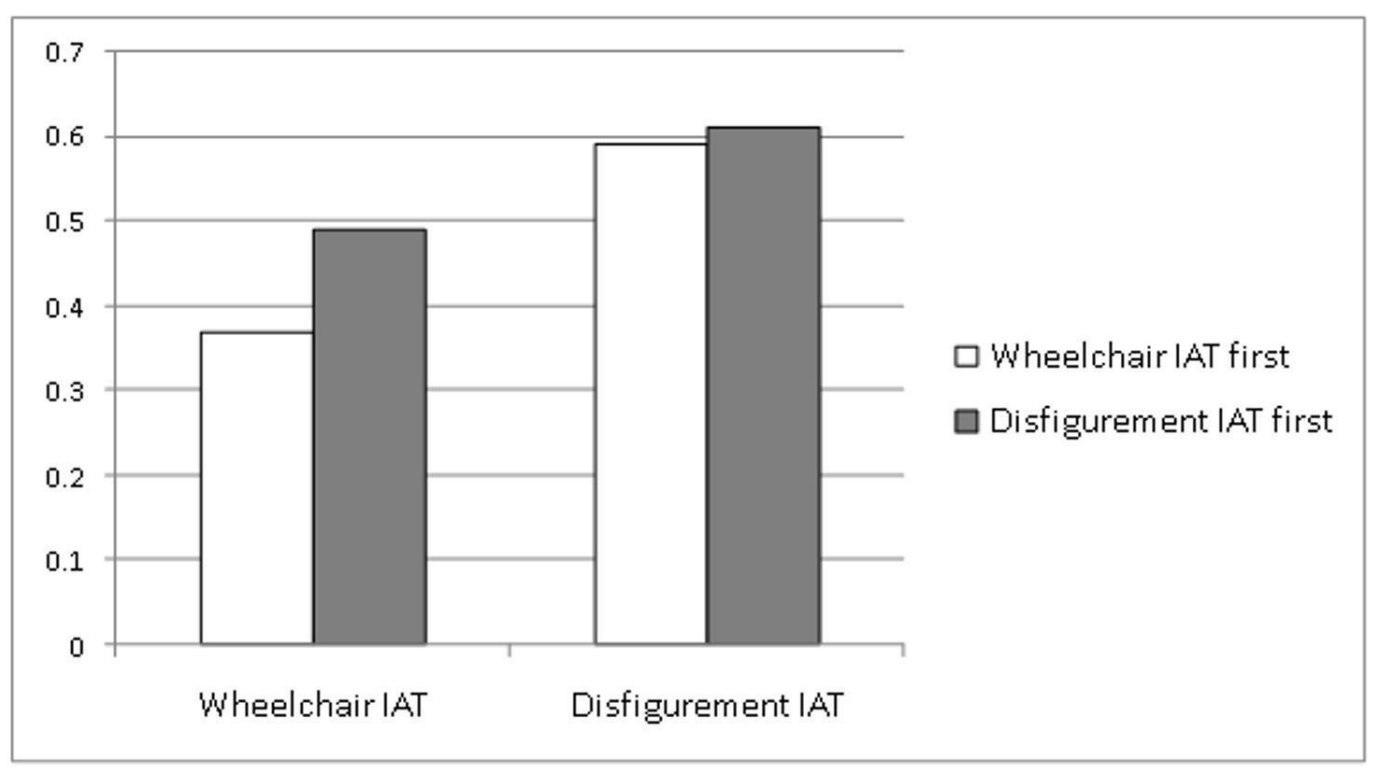

Figure 2: Implicit Association Test effect for people with facial disfigurement and wheelchair users, calculated according to the algorithm recommended in Greenwald, Nosek and Banaji (2003). 
Additional analyses were performed to examine whether the IAT effect was moderated by the order of blocks within each task, e.g. Good-Typical before Good-Distinctive or vice versa. There was no effect of block order in the disfigurement task or in the wheelchair task [both $t<1.2, \mathrm{~ns}$ ].

Anova was performed only on the wheelchair IAT to check whether the stimuli in the two versions (standing vs. sitting normally) were equivalent. The IAT effect was very similar for these two versions $[t(70)=0.54$, ns] which confirms that the two versions of the stimuli were equivalent in the IAT.

Correlation of IAT-effect with rating differences. The rating difference for facial disfigurement was calculated as the sum of the non-disfigured conditions (standing-non-disfigured plus wheelchair-non-disfigured) minus the sum of the disfigured conditions. The evaluation difference for wheelchair was calculated similarly as the sum of the non-wheelchair conditions (standingnon-disfigured plus standing-disfigured) minus the sum of the wheelchair conditions. These differences were calculated for each of the four composites. A positive rating difference implies discrimination against a person shown as a wheelchair user or with a facial disfigurement.

Correlations between the IAT effects and the rating differences are shown in Table 3. The disfigurement IAT effect correlated with the rating differences for Social potency and Emotional strength; both these factors showed consistent rating differences in favour of people without a facial disfigurement in Experiments 1 and 2. The IAT effect for wheelchair use correlated with the rating differences for Work competence and Social potency; both these factors showed consistent rating differences in Experiment 1 and 2. This pattern of results suggests that implicit attitudes might be at least partly responsible for the explicit rating differences. 
Table3: correlations between the IAT effect / Social Norm score and rating differences.

$\begin{array}{llll}\text { Rating } & \text { Rating } & \text { Rating } & \text { Rating } \\ \text { difference } & \text { difference } & \text { difference } & \text { difference } \\ \text { Work } & \text { Social } & \text { Emotional } & \text { Warmth } \\ \text { Competence } & \text { Potency } & \text { Strength } & \end{array}$

Facial Disfigurement

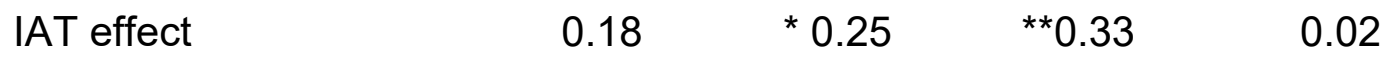

\begin{tabular}{lcccc} 
Social norm score & ${ }^{*} 0.29$ & ${ }^{* *} 0.37$ & 0.14 & ${ }^{*} 0.26$ \\
\hline Wheelchair & & & & \\
IAT effect & ${ }^{* *} 0.34$ & ${ }^{*} 0.26$ & 0.10 & 0.18 \\
Social norm score & ${ }^{*} 0.21$ & 0.18 & 0.15 & -0.14
\end{tabular}

${ }^{*}=p<0.05,{ }^{* *}=p<0.005$

Table 3: correlations among the IAT effect, the perceived social norm, and the rating differences for the four composites Work competence, Social potency, Emotional strength, and Warmth. Upper panel: targets shown with facial disfigurement. Lower panel: targets shown as wheelchair users.

Perceived Social Norms.

The mean score on the Social Norms questionnaire was higher for facial disfigurement [Mean $=3.97$, s.d. $=1.13$ ] than for wheelchair use [Mean $=3.53$, s.d. $=1.05]$. This difference was significant in a paired-samples t-test $[t(71)=2.51, p<0.05]$. The implication is that participants perceived that discrimination against people with facial disfigurement would be more socially acceptable and more commonplace than discrimination against people who use a wheelchair.

Correlations with rating differences are shown in Table 3. The social norm score for facial disfigurement was correlated with the rating difference in Work competence, Social potency, and Warmth. In contrast, the perceived social norm score for wheelchairs was correlated only with the rating difference in Work competence. The stronger pattern of correlation between 
the social norm and ratings differences for disfigurement than for wheelchair use supports the proposition that perceived social norms play a stronger role in discrimination against people with facial disfigurement than wheelchair users.

\section{Discussion}

Persons depicted in a wheelchair were rated as higher on Work competence; higher on Social potency in the non-disfigured condition; and equivalent in Emotional strength and Warmth. Persons depicted with a facial disfigurement were rated as equivalent in Work competence, lower in Social potency, lower in Emotional strength, and higher in Warmth, than those shown without a facial disfigurement This is largely consistent with Experiment 1 and supports hypothesis (1).

There was a larger IAT effect, implying a more negative implicit attitude, for facial disfigurement than for wheelchair use (hypothesis 2). The strength of the negative implicit attitude towards people with facial disfigurement was correlated with the negative difference in rating on the factors of Social potency and Emotional strength (hypothesis 2a). The strength of the negative implicit attitude towards people shown in a wheelchair was correlated with the negative difference in ratings on Work competence and Social potency (hypothesis $2 b$ ). Thus, implicit attitudes seem to be at least partly responsible for explicit evaluation differences.

The perceived social norm for discrimination against people with facial disfigurement was stronger than for discrimination against wheelchair users, supporting hypothesis (3). The correlations between the strength of the perceived social norm and the negativity of photograph ratings for people with facial disfigurement (hypothesis 3a) were stronger than the equivalent correlations for wheelchair users (hypothesis $3 b$ ). This supports the proposition that perceived social norms play a stronger role in discrimination against people with facial disfigurement than wheelchair users.

Gender differences in photograph ratings were sometimes present, and where present they always favoured women over men. The detailed pattern is interesting: women were rated higher on Work competence and Social 
potency when they were shown without a facial disfigurement (Experiment 1) and higher on Warmth when they were shown without any impairment (Experiment 1). This pattern is consistent with de-emphasising of the gender of a disfigured individual although the failure of this pattern to become apparent in Experiment 2 does not permit any strong conclusions. On the factor of Emotional strength there were no gender differences at all; this factor might have been expected to favour men over women, but the positive discrimination shown to women on other factors might have cancelled out this expectation.

It is possible that participants were influenced by the smart dress of the target individuals to infer that the person depicted must be successful in their career. This could explain the higher ratings on Work competence of the wheelchair user and (marginally significant in the data from Experiment 1 and 2 combined) the person with facial disfigurement.

\section{General Discussion.}

Experiments 1 and 2 showed clear differences between the influence of a wheelchair and a facial disfigurement on evaluations of personal and workrelevant traits. People shown in a wheelchair were rated as higher in Work competence (Intelligent, Copes with pressure, Decisive, Shows initiative, Good organisational skills, Good interpersonal skills, and Pays attention to detail ), higher in Social potency (Outgoing, Competitive, Assertive, Prefers teamwork, and Can work with people from different backgrounds), equivalent in Emotional strength (inverse of Sensitive and Emotional and positive Strong leader) and higher in Warmth (friendly and trustworthy) compared to the same people shown standing. In sharp contrast, people with a facial disfigurement were perceived as equivalent in Work competence, lower in Social potency, lower in Emotional strength, and higher in Warmth compared to the same people depicted without a facial disfigurement.

The present results are inconsistent with the literature showing negative perceptions of wheelchair users (e.g. Bell \& Klein, 2001; Fichten \& Amsel, 1986; Kelly et al, 1994; Louvet, 2007; Stone \& Colella, 1996). The apparent positive discrimination for wheelchair users shown in the explicit 
evaluations in the present study is tentatively attributed to the strong ethos for inclusivity and equality present at the University of East London where the majority of participants were recruited. Combined with the negative implicit attitudes it appears that participants may have used their personal values to override negative stereotypes of wheelchair users in order to deliver positive explicit evaluations (e.g. Devine, 1989).

It appears that there was no equivalent process of positive discrimination for individuals shown with facial disfigurement. The conscious control and effortful deliberation that are required to overcome automaticallyactivated stereotypes seems to have been insufficient, with the result being negative explicit evaluations (e.g. Devine, 1989; Greenwald \& Banaji, 1993; Plant \& Devine, 1998).

There are two potential explanations for this failure to override negative stereotypes in the explicit ratings of photographs of people with facial disfigurement. One is the strongly negative affective attitude towards people with facial disfigurement shown in the Implicit Association Test. It seems plausible that a more strongly negative attitude would be more likely to be revealed in explicit ratings. The observation of correlations between the strength of negative implicit attitudes and the difference in explicit ratings of people with and without facial disfigurement supports this reasoning.

The second potential explanation lies in the perception that discrimination against people with facial disfigurement was perceived to be more common and more acceptable than against wheelchair users. The strength of the perceived social norm for discrimination against people with facial disfigurement was correlated with the difference in explicit ratings of people shown with and without facial disfigurement. Finally, a third explanation refers to the extreme nature of the facial disfigurement depicted in the present study. It may be the case that evaluations would be less negative if milder forms of disfigurement were depicted.

The results obtained here for people with facial disfigurement do not agree with the recent study by Stevenage and Furness (2007) which showed no difference in ratings of people with and without a facial disfigurement. An 
explanation for the difference may lie in the stronger degree of disfigurement depicted in the present study compared to the previous paper, but no definite answer can be offered at this point.

A recent increase in contact with wheelchair users may have contributed to their more favourable ratings compared to people with facial disfigurement. The number of wheelchair users in the UK has increased from 710,000 in 1996 (Sapey, Stewart \& Donaldson, 2005) to 1.2 million in 2005 (Department of Health) and participants in the present study were more likely to be close to someone who uses a wheelchair than someone with a facial disfigurement. Inter-group contact can reduce the extent of prejudice towards a disadvantaged group (e.g. Devine, 1989; Dijker \& Raeijmaekers, 1999; Grandfield, Thomson \& Turpin, 2005; Pettigrew \& Tropp, 2006). The implication is that the relative absence from the popular media of people with facial disfigurement may contribute to the maintenance of social prejudice.

A couple of potential limitations of the study will be addressed. Participants in the present studies were asked to respond to still photographs, and while this is not an actual social encounter, there is evidence that responses to still images are predictive of spontaneous behaviour (e.g. Greenwald \& Banaji, 2005). The images of facial disfigurement were genuine but quite extreme, so it is possible that reactions to less extreme forms of disfigurement might have been weaker. This is a question for future research.

In conclusion, target persons depicted with a facial disfigurement were evaluated less favourably on a set of personality traits and competences than were the same persons shown in a wheelchair, compared to controls. More negative implicit attitudes towards people with facial disfigurement, and perceived social norms permitting more discrimination, could help to explain their differences in evaluations. 


\section{$\underline{\text { References }}$}

Andreoni, J. \& Petrie, R. (2008). Beauty, gender and stereotypes: evidence from laboratory experiments. Journal of Economic Psychology, 29, 73-93.

Banse, R., Seise, J. \& Zerbes, N. (2001). Implicit attitudes towards homosexuality: Reliability, validity and controllability of the IAT. Experimental Psychology, 48, 145-160.

Baron, A.S. \& Banaji, M.R. (2006). The development of implicit attitudes: Evidence of race evaluations from ages 6 to 10 and adulthood. Psychological Science, 17, 53-58.

Bell, B.S. \& Klein, K.J. (2001). Effects of disability, gender, and job level on ratings of job applicants. Rehabilitation Psychology, 46, 229-246.

Berry, D. S. \& Wero, J. L. F. (1993). Accuracy in face perception: A view from ecological psychology. Journal of Personality, 61, 497-520.

Blanton,H. \& Jaccard,J. (2006). Arbitrary metrics in psychology. American Psychologist, 61, 27-41.

Bull, R. \& David, I. (1986). The stigmatizing effect of facial disfigurement. Journal of Cross-Cultural Psychology, 17, 99-108.

Clarke, A. (1999) Psychosocial aspects of facial disfigurement: problems, management and the role of a lay-led organisation. Psychology, Health \& Medicine, 4, 127-142.

Cunningham,W.A., Preacher,K.J. \& Banaji,M.R. (2001). Implicit attitude measures: consistency, stability and convergent validity. Psychological Science, 12, 163-170.

Dasgupta, N. \& Greenwald, A.G. (2001). On the malleability of automatic attitudes: Combating automatic prejudice with images of admired and disliked individuals. Journal of Personality and Social Psychology, 81, 800-814. 
Devine, P.G. (1989). Stereotypes and prejudice: Their automatic and controlled components. Journal of Personality and Social Psychology, 56, 518.

Dijker, A.J. \& Koomen, W. (2001). The influence of perceived suffering and vulnerability on the experience of pity. European Journal of Social Psychology, 31, 659-676.

Dijker,A.J. \& Raeijmaekers,F. (1999). The influence of seriousness and contagiousness of disease on emotional reactions to ill persons. Psychology and Health, 14, 131-141.

Eagly, A.H., Ashmore, R.D., Makhijani, M.G. \& Longo, L.C. (1991). What is beautiful is good, but... A meta-analytic review of research on the physical attractiveness stereotype. Psychological Bulletin, 110, 109-128.

Fazio, R.H., Sanbonmatsu, D.M., Powell, M.C. \& Kardes, F.R. (1986). On the automatic activation of attitudes. Journal of Personality and Social Psychology, 50, 229-238.

Fichten,C.S. \& Amsel,R. (1986). Trait attributions about college students with a physical disability: Circumplex analyses and methodological issues. Journal of Applied Social Psychology, 16, 410-427.

Fiske, S.T., Cuddy, A.J.C., Glick, P \& Xu, J. (2002). A model of (often mixed) stereotype content: Competence and warmth respectively follow from perceived status and competition. Journal of Personality and Social Psychology, 82, 878-902.

Gawronski, B. \& Bodenhausen, G.V. (2007). Unraveling the processes underlying evaluation: Attitudes from the perspective of the ape model. Social Cognition, 25, 687-717.

Giancoli, D.L. \& Neimeyer, G.J. (1983). Liking preferences towards handicapped persons. Perceptual and Motor Skills, 57, 1005-1006.

Grandfield, T.A., Thomson, A.R. \& Turpin, G. (2005). An attitudinal study of responses to a range of dermatological conditions using the implicit association test. Journal of Health Psychology, 10, 821-829. 
Greenwald, A.G. \& Banaji, M.R. (1995). Implicit social cognition: attitudes, self-esteem, stereotypes. Psychological Review, 102, 4-27.

Greenwald,A.G., McGhee,D.E. and Schwartz,J.L.K. (1998). Measuring individual differences in implicit cognition: The implicit association test. Journal of Personality and Social Psychology, 74, 1464-1480.

Greenwald, A.G., Nosek, B.A. \& Banaji, M.R. (2003). Understanding and using the Implicit Association Test: I. An improved scoring algorithm. Journal of Personality and Social Psychology, 85, 197-216.

Greenwald,A.G., Nosek,B.A. \& Sriram,N. (2006). Consequential validity of the Implicit Association Test: Comment on the article by Blanton and Jaccard. American Psychologist, 61, 56-65.

Gregg,A.P. (2008). Oracle of the unconscious or deceiver of the unwitting? The Psychologist, 21, 762-766.

Hearst, D. \& Middleton, J. (1997). Psychological interventions and model of current working practice. In R.Lansdown, N.Rumsey, E.Bradbury, T.Carr and J.Partridge (Eds) Visibly Different: Coping with Disfigurement. Butterworth-Heinemann.

Hofmann,W., Gawronski, B., Gschwender,T., Le,H. \& Schmitt, M. (2005). A meta-analysis on the correlation between the Implicit Association Test and explicit self-report measures. Personality and Social Psychology Bulletin, 31, 1369-1385.

Houston, V. \& Bull, R. (1994). Do people avoid sitting next to someone who is facially disfigured? European Journal of Social Psychology, 24, 279284.

Judge, T.A., Hurst, C. \& Simon, L.S. (2009). Does it pay to be smart, attractive, or confident (or all three)? Relationships among general mental ability, physical attractiveness, core self-evaluations, and income. Journal of Applied Psychology, 94, 742-755.

Kelly, A.E., Sedlacek, W.E. \& Scales, W.R. ( 1994). How college students with and without disabilities perceived themselves and each other. Journal of Counselling and Development, 73, 178-182. 
Loo, R. (2001). Attitudes of management undergraduates towards persons with disabilities: A need for change. Rehabilitation Psychology, 46, 288-295.

Louvet, E. (2007). Social judgment toward job applicants with disabilities: Perception of personal qualities and competences. Rehabilitation Psychology, 52, 297-303.

Nordstrom, C.R., Huffaker, B.J. \& Williams, K.B. (1998). When physical disabilities are not liabilities: The role of applicant and interviewer characteristics on employment interview outcomes. Journal of Applied Social Psychology, 28, 283-306.

Pettigrew, T.F. \& Tropp, L.R. (2006). A meta-analytic test of intergroup contact theory. Journal of Personality and Social Psychology, 90, 751-783.

Plant, E.A. \& Devine, P.G. (1998). Internal and external motivation to respond without prejudice. Journal of Personality and Social Psychology, 75, 811-832.

Popa-Roch, M. \& Delmas, F. (2010). Prejudice implicit association test effects: The role of self-related heuristics. Journal of Psychology, 218, 44-50.

Pruett, S.R. \& Chan, F. (2006). The development and psychometric validation of the disability attitude implicit association test. Rehabilitation Psychology, 51, 202-213.

Pryor, J.B., Reeder, G.D., Yeadon, C. \& Hesson-McInnis, M. (2004). A dual-process model of reactions to perceived stigma. Journal of Personality and Social Psychology, 87, 436-452.

Richetin, J. \& Perugini, M. (2008). When temporal contiguity matters: A moderator of the predictive validity of implicit measures. European Journal of Psychological Assessment, 24, 246-253.

Rumsey, N., Bull, R. \& Gahagan, D. (1986). A developmental study of children's stereotyping of facially deformed adults. British Journal of Psychology, 77, 269-274.

Rumsey, N. \& Harcourt, D. (2004). Body image and disfigurement: issues and interventions. Body Image, 1, 83-97. 
Solnick, S.J., Schweitzer, M.E. (1999). The influence of physical attractiveness and gender on ultimatum game decisions. Organizational Behaviour and Human Decision Processes, 79, 19-215.

Steffens,M.C. (2004). Is the Implicit Association Test immune to faking? Experimental Psychology, 51, 165-179.

Stone, D.L. \& Colella, A. (1996). A model of factors affecting the treatment of disabled individuals in organisations. The Academy of Management Review, 21, 352-401.

Stevenage, S.V. \& Furness, C. (2008). The influence of disfigurement on conversational recall. Journal of Health Psychology, 13, 1113-1118.

Stevenage, S.V. \& McKay, Y. (1999). Model applicants: The effect of facial appearance on recruitment decisions. British Journal of Psychology, 90, 221-234.

Thornhill, R. \& Gangestad, S.W. (1993). Human facial beauty: averageness, symmetry and parasite resistance. Human Nature, 4, 237-269.

Walters, E. (1997). Problems faced by children and families living with visible differences. In R.Lansdown, N.Rumsey, E.Bradbury, T.Carr and J.Partridge (Eds) Visibly Different: Coping with Disfigurement. ButterworthHeinemann.

Zebrowitz, L. A. (1997). Reading Faces: Windows to the Soul? Boulder, Co: Westview Press.

Zebrowitz, L. A., Hall, J.A., Murphy, N.A. \& Rhodes, G. (2002). Looking smart and looking good: Facial cues to intelligence and their origins. Personality and Social Psychology Bulletin, 28, 238-249. 


\section{Appendix 1: examples of stimuli used in the evaluation tasks}

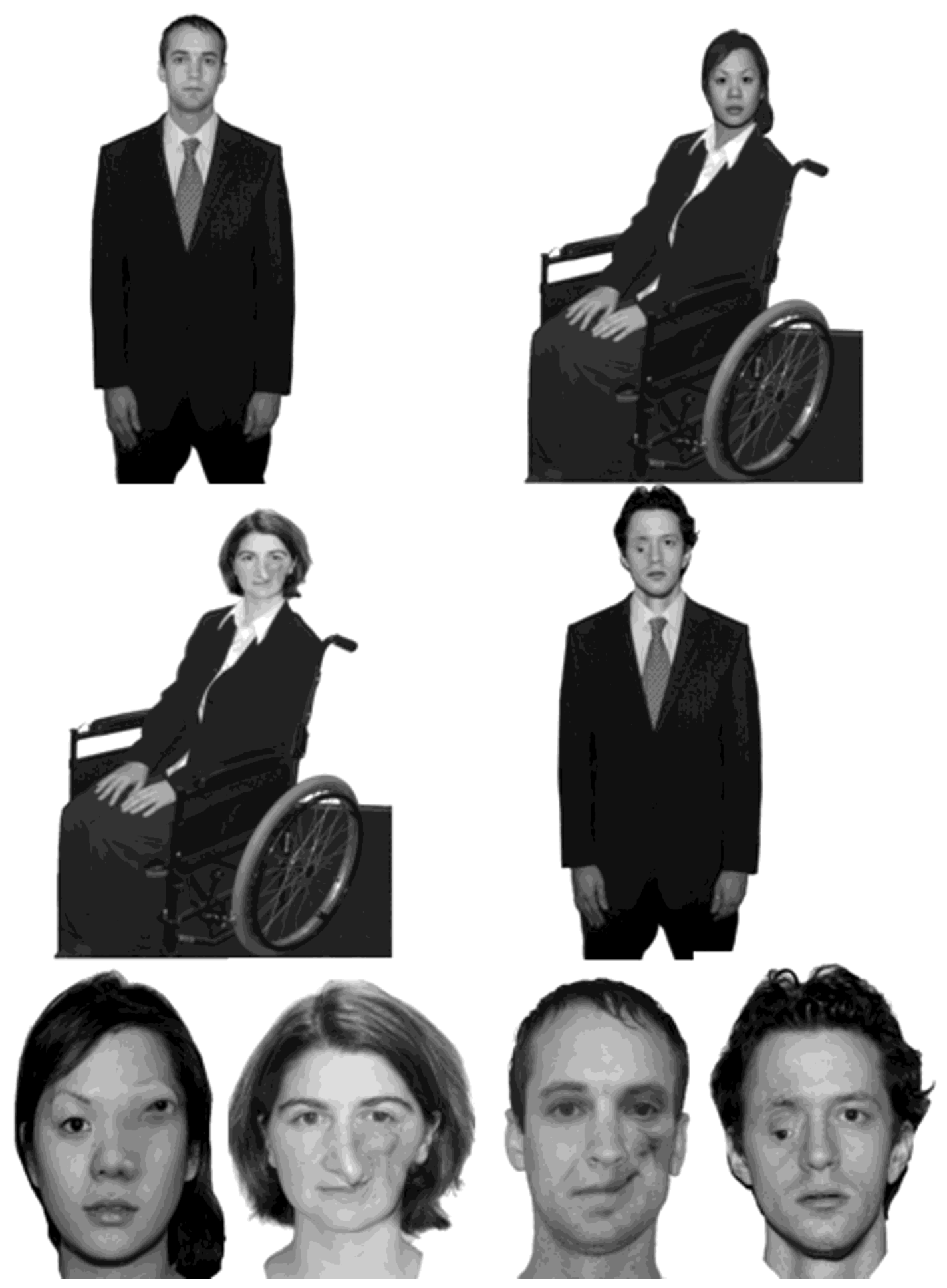


Stimuli used in the Implicit Association Test
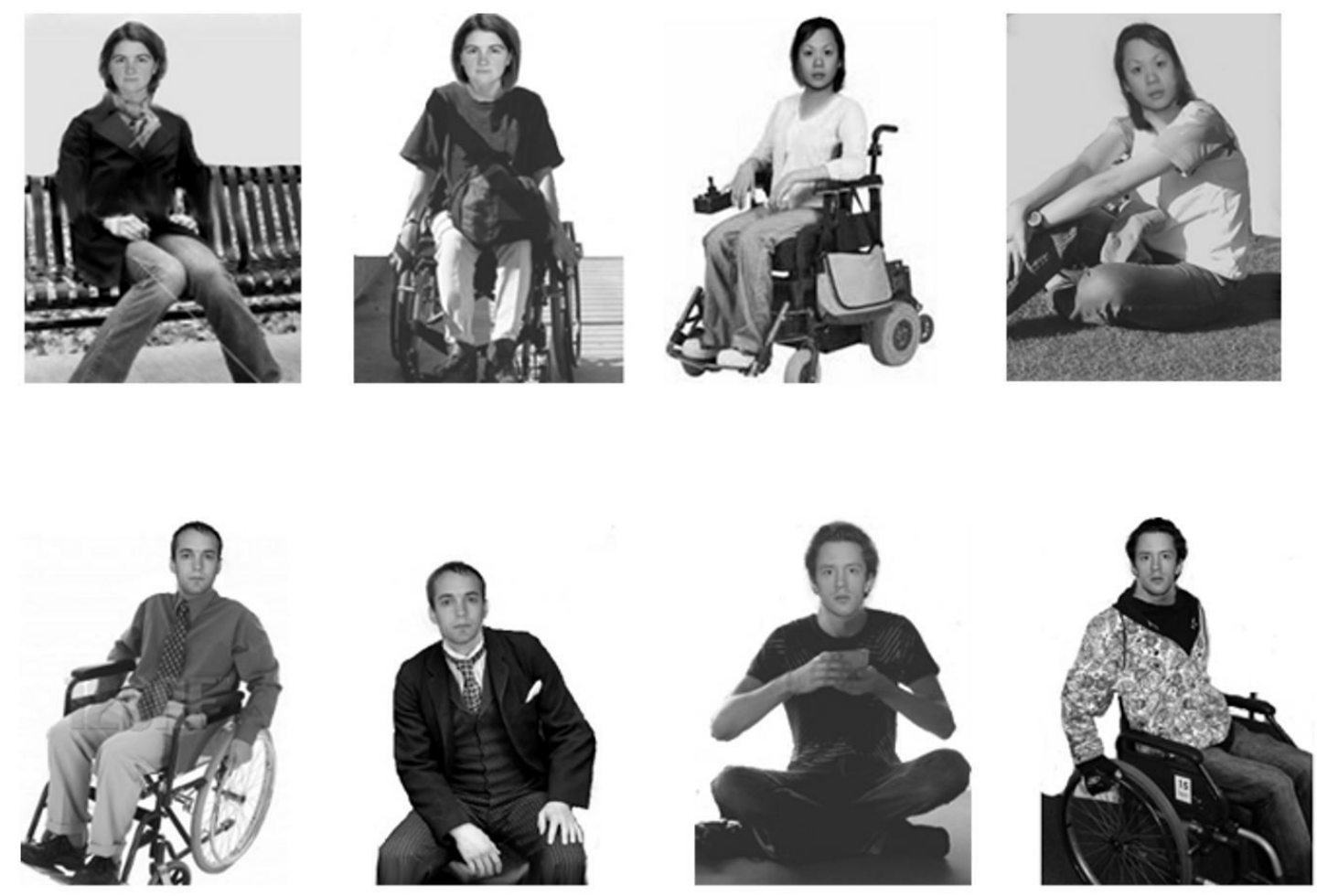


\section{Appendix 2 - Rating terms in Experiments 1-2}

\section{Work competence}

intelligent

copes with pressure

decisive

shows initiative

good organisational skills

good interpersonal skills

pays attention to detail

\section{Social Potency}

outgoing

competitive

assertive

prefers teamwork

can work with people from different backgrounds

\section{Emotional Strength}

sensitive

emotional

strong leader

Warmth

friendly

trustworthy

Not included in any composite

attractive unintelligent

doesn't like pressure

indecisive

shows little initiative

poor organisational skills

poor interpersonal skills

no attention to detail

introverted

non-competitive (passive)

diffident

works best alone

prefers to work with similar people

insensitive

impassive

prefers to follow

unfriendly

undependable

unattractive 


\section{Appendix 3 - Social Norms questionnaire}

These questions concern perceived social norms for the treatment of people who use a wheelchair. All your responses will be completely confidential so please answer honestly. We are not asking how you think or behave, but how you perceive that others think or behave.

$$
\begin{array}{lllllllll}
\text { strongly } \\
\text { disagree }
\end{array}
$$

Other people often behave in a prejudiced way towards a person who uses a wheelchair.

It is morally acceptable to display prejudice towards someone who uses a wheelchair.

It is rare to hear someone talking unfavourably about a person who uses a wheelchair.

Discrimination against a person who uses a wheelchair is not acceptable.

$\begin{array}{lllllllll}1 & 2 & 3 & 4 & 5 & 6 & 7 & 8 & 9\end{array}$

Discriminating against a person who uses a wheelchair is a rare occurrence.

$\begin{array}{lllllllll}1 & 2 & 3 & 4 & 5 & 6 & 7 & 8 & 9\end{array}$

Other people rarely behave in a prejudiced way towards a person who uses a wheelchair.

$\begin{array}{lllllllll}1 & 2 & 3 & 4 & 5 & 6 & 7 & 8 & 9\end{array}$

Discrimination against a person who uses a wheelchair is usually acceptable. $\begin{array}{lllllllll}1 & 2 & 3 & 4 & 5 & 6 & 7 & 8 & 9\end{array}$

It is common to hear someone talking unfavourably about a person who uses a wheelchair.

It is morally unacceptable to display prejudice towards someone who uses a wheelchair.

Discriminating against a person who uses a wheelchair is an everyday occurrence.

$\begin{array}{lllllllll}1 & 2 & 3 & 4 & 5 & 6 & 7 & 8 & 9\end{array}$

Discrimination against a person who uses a wheelchair is not acceptable. 